\title{
Smart mobility and its impact on the environment
}

\author{
Patrick Jochem ${ }^{1,2}$, Xiao Luo ${ }^{3}$, Marlene O'Sullivan ${ }^{1}$, Stephan Müller ${ }^{4}$ \\ ${ }^{1}$ Department of Energy Systems Analysis, Institute of Networked Energy Systems, German Aerospace \\ Center (DLR), Curiestr. 4, 70563 Stuttgart, Germany, tel: +49 7116862687. \\ ${ }^{2}$ Karlsruhe Institute of Technology (KIT), Institute for Industrial Production (IIP), jochem@kit.edu \\ ${ }^{3}$ College of Transportation Engineering, Tongji University, luo.xiao@tongji.edu.cn, tel: +86-021- \\ 65986491
}

${ }^{4}$ Institute of Transport Research, German Aerospace Center (DLR), Rudower Chaussee 7, 12489 Berlin, Germany, stephan.mueller@dlr.de, tel: +49 30 67055-149.

The globally rapidly increasing number of cars as well as mobility demands, climate change, scarce resources, overcrowded megacities with poor air quality are putting pressure on transport systems. Smart mobility concepts, or Mobility-as-a-Service, appear to be an attractive solution to many of these challenges (e.g. Polydoropoulou et al. 2020). Innovations in the field of information and communication technology (ICT) can serve as a key technology for this purpose and activate considerable potentials, especially by influencing traffic habits (cf. Jochem et al., coming forward). Shared autonomous electric vehicles in multimodal transport systems relying only on renewable energy resources are still a vision, but their technical implementation seems realistic due to the developments of recent years (e.g. Sprei, 2018). These visionary transport systems are expected to be more convenient, less costly, better for our health (as long as active modes are integrated) and have much lower environmental impacts than current systems. So, the dependency of smart mobility and the environment is obvious and we hope that smart mobility can serve as a "white knight" for several challenges in the current transportation system.

From a Multi-Level Perspective (MLP, Geels, 2010) point of view, it seems that the time is ripe for bringing the promising technological developments in the automotive sector ("smart mobility") together with the increasing socio-political pressure, which mainly results from the excessive environmental degradation (cf. Figure 1). While in the past, the development of transport volumes knew one direction only - i.e. the techno-economic as well as socio-political pressure was mainly in favour of further growth in transport volumes -current developments in socio-political pressure (e.g. environmental degradation and climate change), current techno-economic paradigms (e.g. digitalisation and autonomization) as well as other socio-cultural developments (e.g. sharing economy) is leading to a situation where this trend might be changed. Together with the current pandemic crises of the SARS-CoV-2 virus, when home-office became a status-quo for many office workers and car registrations decrease (however, with an even stronger decrease in usage of public transportation), a promising and fruitful bed has emerged for potential disruptive innovations in the transport sector. While the passenger car has been a prestigious good (or Veblen good) in the past, the younger generation considers transport more factual; the Mobility-as-a-Service concept is in 
many parts of the world already reality (Polydoropoulou et al. 2020). The way to this multi-modal transport system seems short. However, the main obstacles are still the underestimated costs of passenger car ownership (Andor et al. 2020) and the inertia to change one's behaviour (where the current pandemic might give already a first impulse into the right direction). Overall, the changes toward automation, environmental friendliness, and service orientated mobility are similar to the changes for the transportation system that resulted from the first and second industrial revolutions (cf. Figure 1). In this analogy, it is expected that disruption and improvement in the transportation sector may emerge soon.

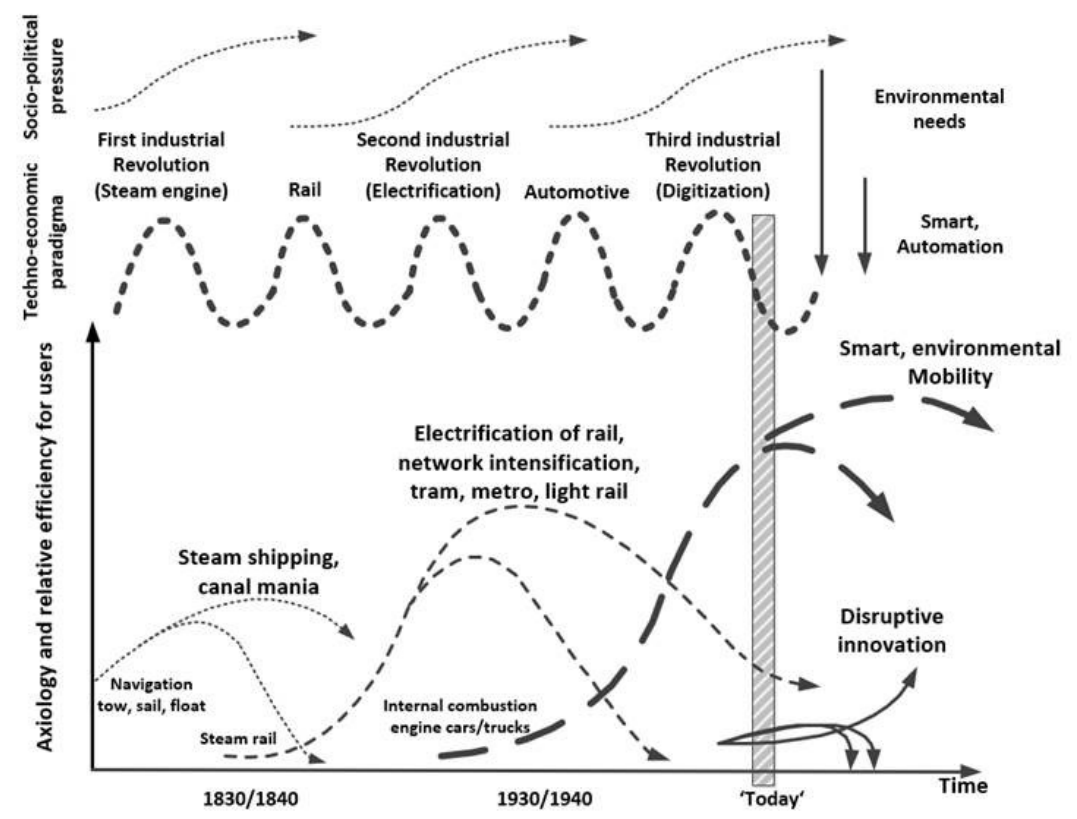

Figure 1: The coherence of smart mobility and the environment in a Multi-Level Perspective (MLP) context (modified, based on Müller, coming forward)

In that vein, we took advantage of the $15^{\text {th }}$ World Conference of Transport Research Society (WCTRS) in Mumbai to discuss and select most recent scientific studies from different disciplines in this field within several sessions organized by the two Special Interest Groups (SIG) "Transport, Climate Change and Clean Air" (SIG F2) and "Smart Transport, Smart City and Quality of Life" (SIG F3). This special issue can be interpreted as a follow-up of the special issue Jochem et al. (2016 and 2018). As a result, five papers are selected which focus on different aspects in this comprehensive research field. They are scheduled as follows: We start with an agent-based analysis on an innovative urban transport system service in Italy before a vehicle simulation model for accounting empirical greenhouse gas emissions from passenger cars is presented. Next, two modes are highlighted, namely electric vehicles and an innovative labelling concept for aviation. Finally, a comprehensive indicator system for measuring the Quality of Life (QoL) in urban areas is developed and implemented for Indian cities. The following sections give a short introduction into the five papers.

Giuseppe Inturri, Nadia Giuffrida, Matteo Ignaccolo, Michela Le Pira, Alessandro Pluchino, Andrea Rapisarda, and Riccardo D'Angelo draw the attention to social exclusion and disadvantages of those persons which have poor access to transport systems (Inturri et al., 2021). In their contribution "Taxi vs. demand responsive shared transport systems: an agent-based simulation approach" they consider current developments in ICT for facilitating the market update of Demand Responsive Shared Transport (DRST) services, which can provide easily accessible and economic-favorable 
mobility services. The authors base their research on several scenarios in an agent-based simulation tool for the city of Ragusa (Italy). They state that these services might contribute to mitigating greenhouse gas emissions and may also improve the system efficiency - but may depend on specific system characteristics, which should be analyzed in further studies.

Caterina Mogno, Georgios Fontaras Vincenzo Arcidiacono, Dimitrios Komnos, Jelica Pavlovic, Biagio Ciuffo, Michail Makridis, and Victor Valverde developed a convincing vehicle simulation model $\mathrm{CO}_{2} \mathrm{MPAS}$ for evaluating the greenhouse gas emissions form empirical mobility patterns, which is nicely introduced in their contribution "The application of the $\mathrm{CO}_{2} \mathrm{MPAS}$ model for vehicle $\mathrm{CO}_{2}$ emissions estimation over real traffic conditions". They explain in detail the uncertainty which occur in greenhouse gas emissions from vehicles during everyday trips in Europe (Mogno et al., 2021). The model is based on empirical emission data from portable emissions measurement systems and shows very accurate results. The $\mathrm{CO}_{2} \mathrm{MPAS}$ model can, therefore, be used for assessing the greenhouse gas emissions in further passenger car micro-simulation exercises.

Eglantine Künle and Christine Minke focused on electric vehicles and their environmental impact by a comprehensive analytical tool integrating a national adoption path identification framework and a macro-environmental STEPE (socio-cultural, technological, economic, political, environmental) approach (Künle and Mike, 2021). In their contribution "Macro-environmental comparative analysis of e-mobility adoption pathways in France, Germany and Norway" the authors apply a case study for different policy measures for electric vehicles in Norway, France, and Germany and found out that technology alone cannot solve our comprehensive environmental challenges.

Stefan Baumeister, Cheng Zeng, and Alex Hoffendahl focus on aviation, which is a very challenging issue in terms of greenhouse gas mitigation on the global scale (Baumeister et al., 2021). In their contribution "The effect of an eco-label on the booking decisions of air passengers" they developed a promising eco-labeling concept which may influence user behavior by branding more polluting flights accordingly. They accomplished a comprehensive stated choice experiment with 553 air passengers and approved the impact from these labels on the customer behavior. Even though this effect seems to be small, an individual adjustment of this label to different customer types may increase its impact.

Finally, Gopal R. Patil and Gajanand Sharma developed a comprehensive QoL score using Principal Component Analysis (PCA) to quantify the relative holistic urban development of 14 Indian cities using 29 indicators grouped into seven components which considers all dimensions of a sustainable transport system (Patil and Sharma, 2021). Their contribution "Urban Quality of Life: An assessment and ranking for Indian cities" shows significant insights to the urban planners on the policy decisions that improve the QoL in cities.

Overall this special issue provides only a small piece of current research on environmental impacts by smart mobility. There is obviously still a high need for further interdisciplinary research on this fast developing and complex topic. We are looking forward to this fast-developing interdisciplinary research stream and are optimistic that the future transport system will be smarter, more convenient, healthier, cheaper and impacts our environment less severe than our current system. 


\section{Acknowledgments}

We thank all participants of our sessions at the $15^{\text {th }}$ World Conference of Transport Research Society (WCTRS) in Mumbai as well as the helpful comments by the anonymous reviewers. A part of our research was funded within the ÖKONVER project by the German Aerospace Center (DLR).

\section{References}

Andor, M. A., A. Gerster, K.T. Gillingham, and M. Horvath (2020), Running a car costs much more than people think-stalling the uptake of green travel, Nature 580, 453-455.

Baumeister, S., C. Zeng, and A. Hoffendahl (2021), The effect of an eco-label on the booking decisions of air passengers, Transport Policy, doi: 10.1016/j.tranpol.2020.07.009.

Geels, F. W. (2010), Ontologies, socio-technical transitions (to sustainability), and the multi-level perspective, Research policy 39(4), 495-510, doi: 10.1016/j.respol.2010.01.022.

Inturri, G., N. Giuffrida, M. Ignaccolo, M. Le Pira, A. Pluchino, A. Rapisarda, and R. D'Angelo (2021), Taxi vs. demand responsive shared transport systems: an agent-based simulation approach, Transport Policy, doi: 10.1016/j.tranpol.2021.01.002.

Jochem, P., C. Lisson, and A. Khanna (coming forward), The role of coordination costs in mode choice decisions: A case study of German cities.

Jochem, P., P. Plötz, W.-S. Ng, and W. Rothengatter (2018), The contribution of electric vehicles to environmental challenges in transport, Transportation Research Part D: Transport and Environment 64, 1-4, 10.1016/j.trd.2018.06.022.

Jochem, P., W. Rothengatter, and W. Schade (2016), Climate Change and Transport, Transportation Research Part D (Editorial) 45, 1-3, doi: 10.1016/j.trd.2016.03.001.

Künle, E., and C. Minke (2021), Macro-environmental comparative analysis of e-mobility adoption pathways in France, Germany and Norway, Transport Policy, doi: 10.1016/j.tranpol.2020.08.019.

Mogno, C., G. Fontaras, V. Arcidiacono, D. Komnos, J. Pavlovic, B. Ciuffo, M. Makridis, and V. Valverde (2021), The application of the CO2MPAS model for vehicle $\mathrm{CO}_{2}$ emissions estimation over real traffic conditions, Transport Policy, 0.1016/j.tranpol.2020.01.005.

Müller, S. (coming forward), Towards Innovative Transport Systems - Evolution and Ground-Breaking Developments, Springer, Berlin.

Patil, G. R., and G. Sharma (2021), Urban Quality of Life: An assessment and ranking for Indian cities, Transport Policy, doi: 10.1016/j.tranpol.2020.11.009.

Polydoropoulou, A., I. Pagoni, A. Tsirimpa, A. Roumboutsos, M. Kamargianni, and I. Tsouros (2020), Prototype business models for Mobility-as-a-Service, Transportation Research Part A: Policy and Practice 131, 149-162, doi: 10.1016/j.tra.2019.09.035.

Sprei, F. (2018), Disrupting mobility, Energy Research \& Social Science 37, 238-242, doi: 10.1016/j.erss.2017.10.029. 